\title{
Traditional food markets, power relations and waste management: a qualitative study
}

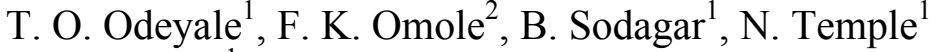 \\ \& C. O'Coill ${ }^{1}$ \\ ${ }^{I}$ School of Architecture, University of Lincoln, UK \\ ${ }^{2}$ Department of Urban and Regional Planning, \\ Federal University of Technology, Akure, Nigeria
}

\begin{abstract}
The rapid urbanization of Sub-Saharan Africa from a purely agrarian society to a city based one is an interesting phenomenon to study. However, recent studies have shown that there is a lack of understanding of socio-cultural factors and subtle power relations that brought about these transformations, especially in developing society. Thus, the paper reports a qualitative study in which interviews were conducted and sizeable numbers of open ended questionnaires were administered and analysed based on the Actor Network Theory. The study examines the often overlooked factors that have impacted on the growth of the built environment, by taking a closer look at the urban centre in relation to the main food market called Oja Oba located in the centre of the city of Akure, Nigeria. During the course of the field research, respondents observed that the general appearance of the city, urban lifestyle and city liveability is directly impacted by the issue of food waste, waste generation and waste disposal. This paper concludes that in the drive towards a sustainable city in the developing world and effective waste management there is need to understand the layers of underlying socio-cultural issues that prompted these changes which are subtle and sometime quite sudden with intended and unintended consequences.

Keywords: anthropology, sustainable development, globalization, social institutions, food market, urbanization.
\end{abstract}




\section{Introduction}

Geoffrey Broadbent [1], in his book Designs in Architecture - architecture and the human sciences; viewed architecture among primitive societies as a manifestation of their daily life, part of which is expressed in their interaction at the traditional marketplace. Foodmarkets in most African societies is a permanent presence of a constant monumental dimension. Hence, investigation into the architecture of the marketplace provides a cherished inter play of physical awareness through which historical, socio-cultural and technological knowledge can be experienced.

Market is a very old concept that dates back to the prehistoric cities of the world. The invention and vitality of the city has much to do with the supply of food through the marketplace [2]. The survival of the city today especially in Africa is due to the versatility of the market as 'a place' (physical entity) and as 'a process' (network of food supply) which may also have intended and unintended consequences such as handling, generation and management of waste.

\section{Dynamics of change, urbanization, persistence of tradition and socio-political dilemma}

The rapid urbanisation of Sub-Saharan Africa from a purely rural-agrarian society to a city based one is an interesting phenomenon to study and it has been of concern to many scholars as documented in several studies [3-8]. The transformation of African society is not only physical but encompasses sociocultural, economic, political and metaphysical in nature. It is also interesting to note that the story of food and food production activities (that connects the markets, home and the city) are locked or intertwined in this rapid transformations and urbanization of post-colonial African society. By looking at on often neglected aspect that involves examining the roles played by socioeconomic activities (such as the food markets) during the course of the rapid urbanisation or transformation and its impact on the built environment as experienced in the study area under review.

Many cities in Nigeria have experienced environmental disintegration and urban decay due to apathy, lack of maintenance culture, poverty large migration from the rural area to the urban centres, ignorance, ineptitude of governmental agencies, inadequate and improper waste disposal mechanism.

Nigeria is an important country, not just in African terms, but in global terms as well. Despite its recent history of economic downturn and unenviable pariah status in the international community, it is a country that cannot be easily ignored. Its history has been a roller coaster ride... and the opening of a new millennium perhaps offers a good historical junction from which to take a critical look at the transformation in the Nigerian state [9]. 
The growth of the Yoruba towns in south west Nigeria in the early 1950's to the oil boom years of 1970 brings about rapid urbanization of its administrative capitals. Shortly after the oil boom came a period of stagnation in physical development and eventual decline or deterioration of both housing quality and the surrounding environment. Travelling through some of the major cities in Nigeria will reveal ample characteristics of blighted urban centres. These urban centres shows symptoms of urban decay such as blocked drainages, bad roads, lack of portable water, inadequate and epileptic power supply derelict and shanty houses and underdeveloped housing environments of the cities (see figure 3).

It has also been suggested that the process of shaping a city (i.e. urbanization) may be due to two principal factors; namely the historical and the political processes [10]. It is evident that rapid urbanization in many African cities such as Akure (the study area) took place in the absence of industrialization. This is contrary to the widely accepted theory on urbanization that strongly linked urbanization to industrialization. Thus, the growth of Akure to a prominent medium-city cannot be described strictly with the word 'planned'. It is more spontaneous and cumulative in nature over several centuries and more rapid urbanization of the last fifty years [11]. Hence, the traditional foodmarkets being an integral part of the social infrastructure of the city; has influenced (and at the same) is also been affected by the political, cultural and socio-economic transformations in the larger society. These transformations are often accompanied with subtle and sometime quite sudden unintended consequences such as waste issues impacting on the environment.

\subsection{The study area}

As earlier state, the study area is located in Akure, Nigeria (see figure 1). Nigeria is a country of over 150 million people; situated to the south between the

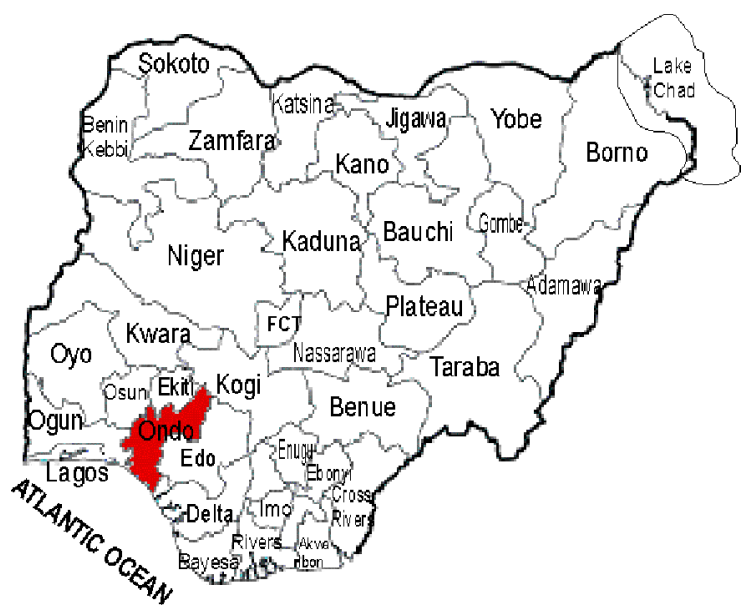

Figure 1: $\quad$ Map of Nigeria. 
Atlantic coasts, the vast rainforest of West Africa and the encroaching Sahara desert to the north. It the most populous black nation in the world and for every five African, one is a Nigerian. Many scholars have regarded Nigeria as the most urbanised nation in Africa [12, 13]. Akure occupies a total land area of 2,303 square kilometres. It lies within 6094' - 7025' $\mathrm{N}$ and 5005' - 5040'E. It is $205 \mathrm{~km}$ from Ibadan and $346 \mathrm{~km}$ from Lagos. The National Population Commission census in 2006 put the census population figure at 353,211. Other minor settlements in close proximity to Akure include Oda Aponmu, Ipinsa, Iwoye, Ajipowo, Igbatoro, Adofure and Isagba. The choice of Akure for this study is based on a number of reasons; it is a typical example of a Sub-Saharan African city that has experienced rapid urbanisation in the past 50 years $(1960-2010)$. It has grown from a medium sized agrarian town to a major metropolis that has experienced socio-cultural transformations and developments through the influence of globalisation and neo-colonial ideas.

\section{How actor network theory can help in understanding urban complexities}

Actor Network Theory (ANT) was first used by Michel Callon in the regard to find a neutral vocabulary to describe actions of "heterogeneous engineers" [14, 15]. ANT rests on the idea that relationship between different components of the society "and the strategies that shape it, may be described in a network of vocabulary that emphasise the interrelated and heterogeneous character of all its components both social and technical" [16]. The actor network theory has been useful as a tool to enable a description and analysis of the co-evolution of sociotechnical context and content. The theory claims that innovations takes place within the networks of actors. The "global network" consists of sets of relations between an actor and its neighbours and relations between the neighbours. The global network is also the way attempt to mobilize and stabilize in order to obtain resources to build projects. It is within these networks that interactions may take place among the actors. ANT is also concerned with the stability and instability of emergent states in dynamic system, "which are responding to economic, political and technological changes" [17, 18].

Bruno Latour [19] commenting on Gabriel Tarde, revisited the sociological principles set forth by Gabriel (de) Tarde; a major figure in French sociology at the turn of the 19th century. A careful study of Tarde's viewpoint has led perhaps to rethinking Durkheim's approach to sociological studies. In reaction to the famous sociological dictum Latour [19] assert, "that the whole is more than the sum of its parts"; by borrowing from Tardian principle asserting that "since the smaller is always the more complex and the more explanatory entity, the whole is less than the sum of it. A human society, for example, is less than the sum of its aggregates"; hence, in order to understand complex relationship and interactions in the urban setting, it is imperative to critically review actants that made up the sum of its aggregates [20, 21]. According to Sage et al. [17] it is important to acknowledge the fact that ANT share similarities with some other approaches to organisational theories, however what stand out ANT from others 
is the emphasis on the role of both human and nonhumans in shaping the urban milieu that involves power relationship. In their own words:

What obviously differentiates our ANT account is, of course, the suggestion that power relationship and human cognition might be influenced by nonhumans, from otters to $£ 50$ notes or bagpipes. As nonhuman and human interact, new interest, meanings, actors and roles are revealed which had, in this case, to be translated ... often by inserting new nonhumans and humans [17].

And this can clearly be translated into the urban environmental situation that involves the roles of both human and nonhumans in shaping the built environment especially as suggested in the research findings as shown in figure 2 and also later in table 1.

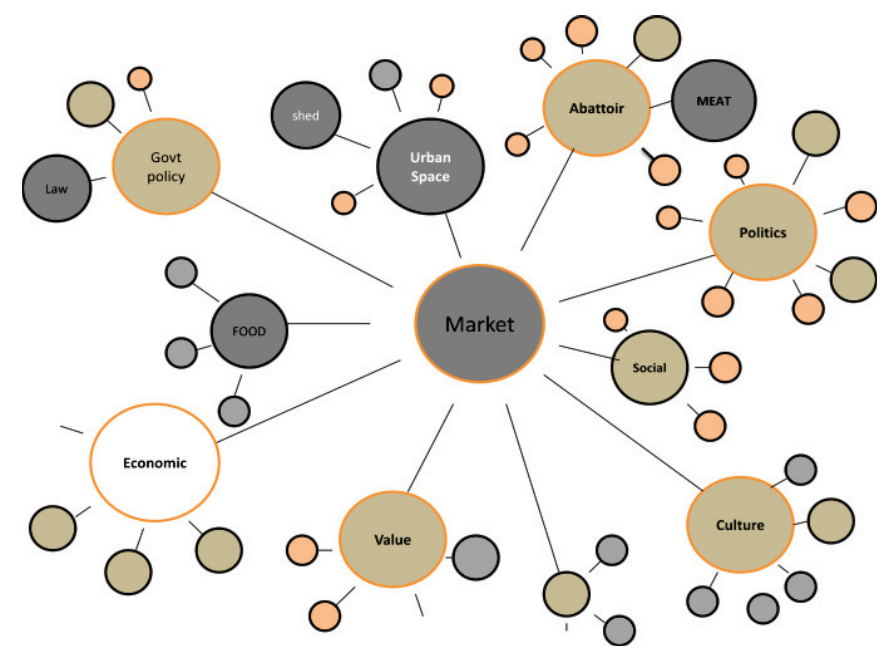

Figure 2: Networks of power relations mapping among actors/respondents involved in foodservices and waste management issues in the study area based on emerging themes from the case interview.

\subsection{Employing ANT as a tool in understanding urban environmental impact assessment}

Market places, people and various food production and consumption activities belong to these "heterogeneous networks derived from confused overlaps" [22, 
Table 1: Thematic content analysis of research finding from the case interview illustrated above.

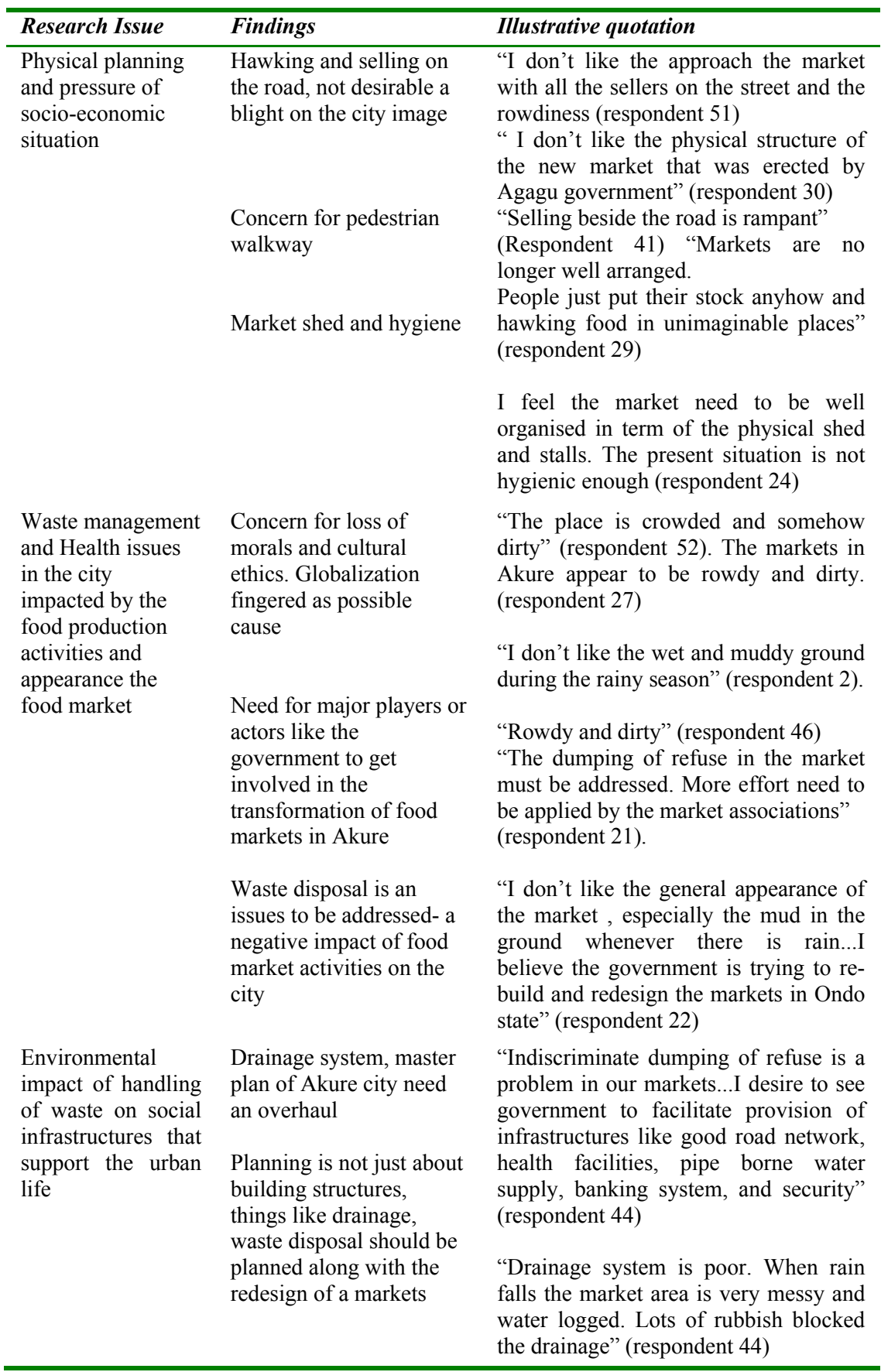


22, 23]. In addition, Bijker [23] identified forces that shape society, such as societal structures, power relations, ingenuity and emotional commitment of stakeholders involved in the schemes of things. It can be broadly argued that any transformation could have taken a different configuration, if different routes had been taken in its process. Bijker and Law [24] argued that societal transformation could have worked better; stating that "our artefacts might have been different, they might have worked better, they might not have failed, (and) they might have been more user and environmental friendly". However, there is the need to remember that the whole history of societal development is not a linear progression or orderly path, neither were they consciously predetermined towards a goal [23].

\section{Research findings: environmental impact of waste management and power relations among actors}

This paper focuses on reporting the qualitative aspect of the research that involves a broader study. The research materials are sourced from data collection that includes mainly in-depth interview, direct observation, questionnaires building demographic and facility survey. Secondary data on health records, available base map of the study area and records from the environmental managers were sourced from the various institutions, ministries and establishments. Population data were obtained from the National Population Commission, Akure and general data on Nigeria. About 1306 buildings existed in the area, out of which 48 were non-residential, leaving 1258 as target population for the study. From this, a sample of $20 \%$ amounting to 252 was selected randomly for questionnaire administration and interview. In selecting the respondents, every $5^{\text {th }}$ house in the five streets involved was taken for interview, usually a household-head per building.

\subsection{Conducting the research interview}

Conversation through interviewing can serve as the ultimate context in which knowledge is understood $[25,26]$. Therefore, the preparation, designing and formulating of the interview questions, was carried out with the understanding that knowledge is constructed from the interview. Through the interaction of the interviewer and interviewee, conversation may be viewed as a basic mode of knowing more about behaviour of users of urban infrastructures such as the foodmarkets and its attendant impact on the built environment. Issues highlighted include socio-political/ development themes of the various actors, (the market users and sellers, government officials) that constitute part of the transformation in built environment in Akure and Nigeria. Also, that human reality may be recast or understood, and such understanding of realities may be methodological, epistemological or ontological in outlook [27].

In this regard, the conduct of the interview was based on an interview guide developed and pre-tested before the actual interview. The interviews were carried out with reflective approach to the knowledge sought. The interpersonal 
relationship with the interviewees before, during and after the process of conversation is done with mutual respect, tact and sense of friendliness. Because, in our culture a lot of greetings and self adulation towards the interviewee need to be in place; in order to create a sense of ambience for meaningful conversation. To elicit people's spontaneous concerns about the state of the food markets and the issues surrounding the social infrastructure such as food waste generation, handling and disposal of waste (especially at the main market Oja Oba) in Akure respondents were asked the following questions:

Q. What is the name of your market?

Q. What particular thing you do not like about markets in your city?

Q. What do you think, in general, are the ways markets have changed from the past ones?

Q. How do you deal with your food waste at home or at the market?

Urban transformations mirrors the complex nature of the society which has social implications, such the general attitude to hygiene, sanitation control and environmental consciousness of the urban populace (this can be compared to the apathy exemplified in pictures - see figure 3). It has been argued that it is practically impossible "to pry apart social, cultural and economic relations" [24]. Therefore, this paper argued that the process that shapes for instance attitudes towards waste handling, disposal and management has a strong link to the way societies were organised. Urban growth or transformation is not an inevitable phenomenon, but rather an unpredictable occurrence based on existing social,
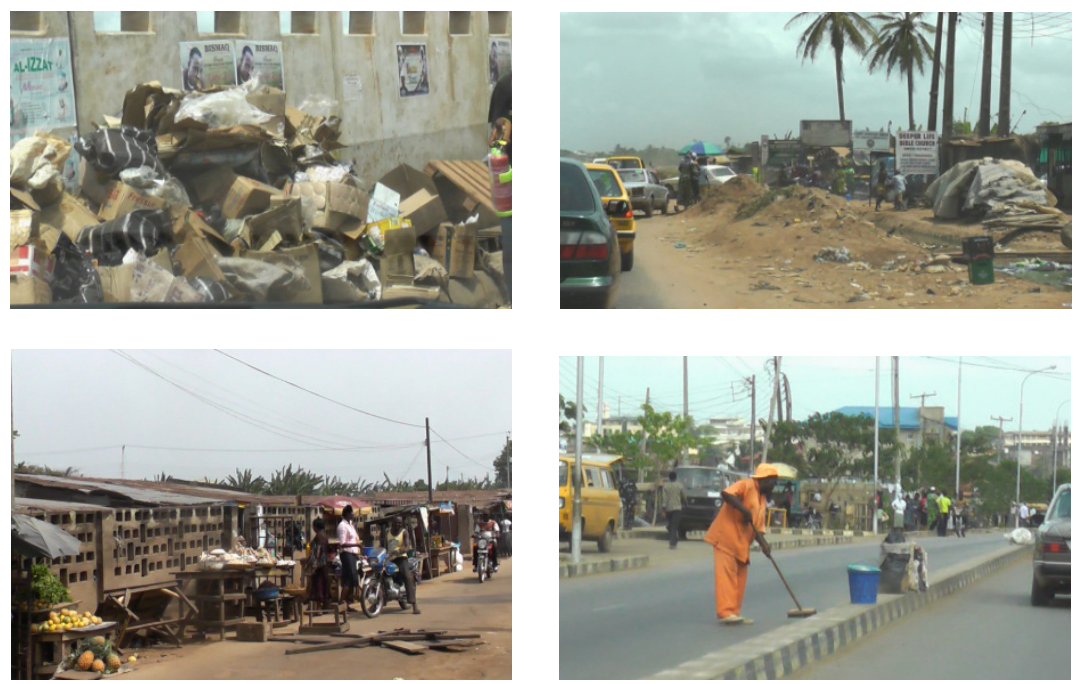

Figure 3: Environmental management problem, garbage and food waste in relation to the foodmarkets and mitigating efforts by the community. 
economic and political relations. Understanding how society functions and works is paramount, since it exposes the complex "trade off and compromises" that shapes it [24]. Hence, this will lead to the people themselves to become better empowered to induce change.

\section{Conclusion}

Examining the foodmarkets as 'a place' and as 'a process' is often a reflector of the life within the city and offers a window into the soul of the city in the developing countries. Therefore, the function of foodmarket as a physical entity that originates with most cities can be closely linked to its role as facilitating food production and consumption and promoting social cohesion with attendant environmental consequences. Thus, this paper suggests that the contemporary structure of the city, especially the urban centres must be enhanced with the provision of specific policies in order to facilitate a holistic development. During the course of the field research, respondents observed that the general appearance of the city, urban lifestyle and city liveability is directly impacted by the issue of food waste, waste generation and waste disposal. Hence, the drive towards a sustainable city in the developing world and effective waste management there is need to understand the layers of underlying socio-cultural issues that prompted these changes which are subtle and sometime quite sudden with intended and unintended consequences.

\section{References}

[1] Broadbent, G., Design in Architecture. Architecture and the human sciences, David Fulton Publishers: London, 1988.

[2] Steel, C., Hungry City: How food shapes our lives, Chatto and Windus: London, pp. 30-69, 2008.

[3] Jamal, V. and Weeks, J., "The vanishing rural-urban gap in Sub-Saharan Africa”, International Labour Review 127 (3), pp. 271-292, 1988.

[4] Jamal, V. and Weeks, J., Africa Misunderstood, Macmillan: London, 1993.

[5] Mabogunje, A.L., Urbanization in Nigeria, University of London Press: London, 1968.

[6] Ellis, F. and Sumberg, J., Food production, urban areas and policy responses, World Development, 26(2), pp. 213-225. 1998.

[7] Drakakis-Smith, D., Bowyer-Bower, T. and Tevera, D., "Urban poverty and urban agriculture: an overview of the linkages in Harare", Habitat International 19(2), pp. 183-193, 1995.

[8] Egziabher, A. G., Lee-Smith, D., Maxwell, D. G., Memon, P. A., Mougeot, L. J. A. and Sawio, C. J., Cities Feeding People: An Examination of Urban Agriculture in East Africa, International Development Research Centre: Ottawa, 1994. 
[9] Oyebade, A., Preface to The Transformation of Nigeria: Essays in Honour of Toyin Falola, African World Press, Inc.: Trenton \& Asmara, pp. xi-xii, 2002.

[10] Welter, V.M., Biopolis: Patrick Geddes and the City of Life, MIT Press: Cambridge, 2002.

[11] Falola, T. and Genova, A., Historical dictionary of Nigeria, Scarecrow Press: Maryland, USA, 2009.

[12] Freund, B. The African City: A History, Cambridge University Press: Cambridge and New York, 2007.

[13] Falola, T., 'The Yoruba caravan system of the nineteenth century', The International Journal of African Historical Studies, 24 (1), pp. 111-132, 1991.

[14] Callon, M. 'An Essay on Framing and Overflowing: Economic Externalities Revisited by Sociology', in Michel Callon (ed.) The Laws of the Markets, Blackwell: Oxford, pp. 244-269, 1998.

[15] Callon, M. and John, L. 'Introduction: Absence-Presence, Circulation, and Encountering in Complex Space', Environment and Planning D: Society and Space, 22, pp. 3-11, 2004.

[16] Law, J. and Callon, M., 'The life and death of the aircraft: A network analysis of technical change', In W.E Bijker and J. Law (Eds.), Shaping technology/building society: Studies in sociotechnical change, MIT: Cambridge, pp. 21-52, 1992.

[17] Sage, D., Dainty, A. and Brookes, N. How actor-network theories can help in understanding project complexities, International Journal of Managing Projects in Business, 4,(2), pp. 274-293, 2011.

[18] Farías, I. and Bender, T., Urban Assemblages: How Actor-Network Theory Changes Urban Studies, Routledge: London, pp. 370-372, 2009.

[19] Latour, B., 'Gabriel Tarde and the End of the Social', in P. Joyce (ed.) The Social in Question: New Bearings in History and the Social Sciences, pp. 117-32. Routledge: London, 2002.

[20] Tarde, G., On Communication and Social Influence: Selected Papers Edited and with an Introduction by Terry N. Clark, University of Chicago Press: Chicago, 1969.

[21] Toews, D., 'The New Tarde: Sociology after the End of the Social', Theory, Culture \& Society, 20, (5), pp. 81-98, 2003.

[22] Law, J., A Sociology of Monsters: Essays on Power, Technology and Dominion, Routledge: London, pp. 21-45, (1991).

[23] Bijker, W. E., Of Bicycles, Bakelites and Bulbs: Toward a theory of sociotechnical change, MIT: Cambridge, pp. 3-35, 1995.

[24] Bijker, W. E., and Law, J., 'Strategies, resources and the shaping of technology'. In: W.E. Bijker and J. Law, (ed.) Shaping technology/ building society-studies in socio-technical change. MIT: Cambridge, 105-106, 1992.

[25] Rorty, R., Philosophy and the mirror of nature, Princeton University Press: New Jersey, 1979. 
[26] Kvale, S., InterViews: An introduction to qualitative research interviewing, Sage: Thousand Oaks, 1996.

[27] Maykut, P.S., and Morehouse, R., Beginning qualitative research: A philosophic and practical guide, Falmer Press: London and Washington, D.C., 1994. 